\title{
IMPLEMENTASIGOOD CORPORATE GOVERNANCE DAN PERAN DEWAN PENGAWAS SYARIAH DI BANK SYARIAH
}

\author{
Akhmad Faozan \\ Dosen Jurusan Syariah Prodi Ekonomi Islam Sekolah Tinggi Agama Islam Negeri (STAIN) \\ Purwokerto \\ Mahasiswa Program Doktor pada Program Pasca Sarjana Prodi Ekonomi Islam Universitas Islam \\ Negeri (UIN) Sunan Kalijaga Yogyakarta \\ e-mail:afa_ozan@yahoo.com
}

\begin{abstract}
Abstrak
Seiring perkembangan bank syariah sebagaimana tampak pada beragamnya produk dan jasa yang diberikan, maka penerapan tata kelola perusahaan yang baik di lembaga keuangan ini pun semakin penting. Penerapan tata kelola perusahaan yang baik pada bank syariah hendaknya mengacu pada lima prinsip yaitu transparansi, akuntabilitas, tanggung jawab, dan kewajaran. Untuk menerapkan prinsip-prinsip tersebut, bank harus menyesuaikan dengan prinsip Islam dalam operasional perbankan. Oleh karena itu, peranan Dewan Pengawas Syariah (DPS) dalam penerapan tata kelola perusahaan yang baik pada bank syariah menjadi sangat penting untuk mengawasi dan menjamin bahwa operasional bank telah sesuai dengan prinsip Islam. Peranan DPS dalam penerapan tata kelola perusahaan yang baik pada bank syariah meliputi mengontrol, menilai, dan mensupervisi aktivitas pada lembaga keuangan syariah untuk menjamin kesesuaian dengan prinsip dan aturan syariah. DPS juga harus mendiseminasikan dan mengedukasi masyarakat melalui media yang ada di masyarakat seperti khutbah maupun majlis ta'lim.
\end{abstract}

Kata Kunci: tata kelola perusahaan yang baik, Dewan Pengawas Syariah, bank syariah

\begin{abstract}
Along with the development of Islamic banks, characterized by the diversity of bank products and bank service network grows, the implementation of Good Corporate Governance (GCG) in Islamic banks becomes increasingly important. Implementation of GCG in Islamic banks should be based on five principles, namely transparency, accountability, responsibility, professional and fairness. To implement those principles, bankshave tobe in accordancewith theprinciplesof Islamicin bank's operation. Therefore, the role ofthe Sharia Supervisory Board (SSB) in the implementation of good corporate governancein Islamic banksis very important to over see and ensure that a bank operation has been in accordance with Islamic principles. The roles for SSB in the implementation of GCG principlesin Islamic banks is directing, reviewing and supervising the activities of Islamic Financial Institution in orderto ensure that they are in compliance with Islamic shari'a rules and principles. The SSB also has to disseminate and educate the public about Islamic banking through the media that has been running in the community, such askhutbah and majelista'lim.
\end{abstract}

Keywords: good corporate governance, sharia supervisory board, Islamic bank 


\section{PENDAHULUAN}

Pertumbuhan dan perkembangan perbankan syariah yang begitu pesat akhir-akhir ini ditandai dengan semakin bertambahnya jumlah jaringan pelayanan bank syariah dan semakin beragamnya produk menyebabkan penerapan Good Corporate Governance (GCG) pada perbankan syariah menjadi semakin penting. ${ }^{1}$ GCG yang berfungsi untuk mengantisipasi berbagai macam risiko, baik risiko finansial maupun reputasi, juga merupakan pilar penting yang harus diterapkan untuk mewujudkan bank syariah yang unggul dan tangguh. Penerapan GCG di bank syariah menjadi penting mengingat bank syariah merupakan bank yang menggunakan prinsip profit sharing (keuntungan dibagi bersama antara bank dan nasabah). ${ }^{2}$

Implementasi GCG di perbankan syariah dalam rangka menjadikan bank syariah menjadi lebih syar'i karena penerapannya pada industri perbankan syariah harus memenuhi prinsip syariah. Operasional perbankan syariah harus benar-benar dijalankan berdasarkan prinsip syariah. Di sisi lain, arah pengembangan dan regulasi perbankan syariah adalah untuk memastikan kepatuhan terhadap prinsip syariah (sharia compliance) dalam operasionalnya dengan melaksanakan fatwa-fatwa yang sudah dikeluarkan oleh Dewan Syariah Nasional (DSN) Majelis Ulama Indonesia (MUI).

GCG merupakan suatu sistem pengelolaanperbankanyang dirancang untuk meningkatkan kinerjabank, melindungi kepentinganstakeholders dan meningkatkan kepatuhan terhadap peraturan perundang-undangan serta nilai-nilai etika yang berlaku secara umum. Oleh sebab itu, untuk membangun kepercayaan masyarakatkepada bank syariah dan menjamin kepatuhan terhadap prinsip syariah,diperlukan pelaksanaan GCG sebagai syarat bagi bank syariah untuk berkembang dengan baik dan sehat. ${ }^{3}$

Agar penerapan GCG lebih efektif di perbankan syariah, Bank Indonesia telah mengeluarkan Peraturan Bank Indonesia (PBI) Nomor 11/33/PBI/2009 yang selanjutnya dilengkapi dengan Surat Edaran Bank Indonesia (SEBI) tentang Pelaksanaan GCG di Bank Umum Syariah (BUS) dan Unit Usaha Syariah (UUS). Sejak dikeluarkannya PBI tersebut, bank syariah berkewajiban menerapkan GCG dan melakukan self assessment serta kemudian membuat laporan tentang penerapan GCG dalam laporan tahunannya.

Penerapan GCG di bank syariah dan konvensional menggunakan prinsip-prinsip yang sama, yaitutransparansi, akuntabilitas, pertanggungjawaban, profesional dan

${ }^{1}$ Penjelasan Atas Peraturan Bank Indonesian (PBI) No. 11/33/PBI/2009 Tentang Pelaksanaan Good Corporate Governance (GCG) Bagi Bank Umum Syariah (BUS) dan Unit Usaha Syariah (UUS) pada bagian Umum.

${ }^{2}$ M. Umer Chapra dan Habib Ahmed (2002). Islamic Governance In Islamic Financial Institutions (Jeddah: Islamic Research dan Islamic Institute, Islamic Development Bank), pp. 50-71.

${ }^{3}$ Moh. Wahyudin Zarkasyi (2008). Good Corporate Governance Pada Perusahaan Badan Usaha Manufaktur, Perbankan Dan Jasa Keungan Lainnya (Bandung: Alfabeta), p. 35. 
kewajaran. ${ }^{4}$ Penerapan GCG di bank syariah harus memenuhi kepatuhan pada prinsip syariah (sharia compliance). ${ }^{5}$ Implementasi GCG di bank syariah tidak bisa dipisahkan dari kewajibannya untuk menjalankan kegiatan usaha yang berdasarkan prinsip syariah. Hal inilah yang membedakannya dengan penerapan GCG di bank konvensional. Karenanya, peranDewan Pengawas Sayriah (DPS) dalam implementasi GCG menjadi sangat penting yaitu sebagai pihak yang mengawasi dan memastikan bahwa suatu bank syariah dalam operasionalnya telah sesuai dengan prinsip syariah.

DPS merupakan badan independen yang ditempatkan pada suatu bank syariah yang berperan mengawasi penerapan prinsip syariah dalam kegiatan usaha bank. Anggotanya terdiri dari pakar di bidang fiqh muamalah yang mengetahui pengetahuan umum di bidang perbankan dan kemampuan lain yang relevan dengan tugas kesehariannya. ${ }^{6}$ DPS dalam mengawasi operasional bank syariah wajib mengacu kepada fatwa DSN untuk memastikan kesesuaian produk dan jasa bank dengan ketentuanketentuan dalam fatwa tersebut.

Berangkat dari latar belakang masalah di atas, tulisan ini akan mengkaji tentang implementasi GCG dan peran DPS di bank syariah. Setelah pendahuluan,dilanjutkan dengan pembahasan tentang GCG yang meliputi pengertian dan implementasinya di bank syariah. Kemudian, dilanjutkan dengan pembahasan tentang DPS yang mengupas tentang pengertian dan perannya dalam implementasi GCG di bank syariah. Tulisan ini diakhiri dengan kesimpulan yang merupakan pokok-pokok bahasan yang ada di dalamnya.

\section{GOOD CORPORATE GOVERNANCE (GCG)}

\section{A. Pengertian Good Corporate Governance (GCG)}

Sampai saat ini para ahli masih menghadapi kesulitan dalam mendefinisikan GCGyang dapat mengakomodasi berbagai kepentingan. Tidak terbentuknya definisi yang dapat mengakomodasi semua pihak disebabkan karena cakupan GCG yang lintas sektoral. GCG dapat didekati dengan berbagai disiplin ilmu, sepertimakroekonomi, akuntansi, keuangan, manajemen, psikologi, sosiologi dan politik.

GCG adalah merupakan suatu istilah yang berasal dari bahasa Inggris, yaitu good yangberarti baik, corporate yang berarti perusahaan dan governance yang berarti pengaturan. Secara umum, istilah good corporate governancediartikan dalam bahasa Indonesia dengan tata kelola perusahaan yang baik. Istilah ini,dalam dunia perbankan,diartikan dengan tata kelola bank yang baik.

${ }^{4}$ Peraturan Bank Indonesia (PB) No. 11/33/PBI/2009 Tentang Pelaksanaan Good Corporate Governance Bagi Bank Umum Syariah Dan Unit Usaha Syariah Pasal 1 ayat 10.

${ }^{5}$ Mervyn K. Lewis dan Latifa M. Algaud (2007). Islamic Banking. Burhan Subrata et al (terj.), Perbankan Syariah (Jakarta: PT Serambi Ilmu Semesta), p. 214.

${ }^{6}$ Muhammad (2011). Audit Dan Pengawasan Syariah Pada Bank Syariah Catatan Pengalaman, (Yogyakarta: UII Press), p. 18. 
Menurut Bank Dunia, CGC adalah aturan, standar dan organisasi di bidang ekonomi yang mengatur perilaku pemilik perusahaan, direktur, dan manajer serta perincian dan penjabaran tugas dan wewenang serta pertanggungjawabannya kepada investor (pemegang saham dan kreditur). ${ }^{7}$ Tujuannyauntuk menciptakan sistem pengendaliaan dan keseimbangan (check and balances) untuk mencegah kemungkinan penyalahgunaan sumber daya perusahaan dan tetap mendorong terjadinya pertumbuhan perusahaan.

Syakhroza mendefinisikan GCG sebagai suatu mekanisme tata kelola organisasi secara baik dalam melakukan pengelolaan sumber daya organisasi secara efisien, efektif, ekonomis ataupun produktif dengan prinsip-prinsip keterbukaan, akuntabilitas, pertanggungjawaban, independen, dan adil dalam rangka mencapai tujuan organisasi. ${ }^{8}$ Tata kelola organisasi yang baik dapat dilihat dari segi mekanisme internal organisasi ataupun mekanisme eksternal organisasi. Mekanisme internal lebih fokus kepada bagaimana pimpinan suatu organisasi mengatur jalannya organisasi sesuai dengan prinsip-prinsip diatas. Sedangkan, mekanisme eksternal lebih menekankan kepada bagaimana interaksi organisasi dengan pihak eksternal berjalan secara harmoni tanpa mengabaikan pencapaian tujuan organisasi.

Organization for Economic Co-Operation and Development (OECD) ${ }^{9}$ mendefinisikan GCG dengan sekumpulan hubungan antara pihak manajemen perusahaan, board dan pemegang saham dan pihak lain yang mempunyai kepentingan dengan perusahaan. ${ }^{10}$ Dalam GCG disyaratkan adanya struktur, perangkat untuk mencapai tujuan dan pengawasan atas kinerja. Implementasi GCG yang baik dapat memberikan perangsang atau insentif yang baik bagi board dan manajemen untuk mencapai tujuan yang merupakan kepentingan bersama.

Peraturan Menteri Negara Badan Usaha Milik Negara (BUMN) menyebutkan bahwaGCGadalah prinsip-prinsip yang mendasari suatu proses dan mekanisme pengelolaan perusahaan berlandaskan peraturan perundang-undangan dan etika berusaha. ${ }^{11}$ Tujuannya adalah untuk mengoptimalkan nilai perusahaan agar memiliki daya saing yang kuat, baik secara nasional maupun internasional, sehingga mampu

7"The Case for Corporate Governance: What Is Corporate Governance?" dikutip dari http://go.worldbank.org/LHV3EZQV10 diakses 6 Juni 2012.

${ }^{8}$ Syakkroza, Akhmad (2008), Corporate Governance, Sejarah dan Perkembangan, Teori, Model dan Sistem Governance Serta Aplikaasinya dan Pada Perusahaan BUMN. Jakarta: Lembaga Penerbitan FEUI.

${ }^{9}$ Organisation for Economic Co-operation and Development (OECD) adalah organisasi untuk kerjasama dan pengembangan ekonomi. OECD merupakan sebuah organisasi internasional dengan tiga puluh negara yang menerima prinsip demokrasi perwakilan dan ekonomi pasar bebas.

${ }^{10}$ Organisation for Economic Co-operation and Development(2004). OECD Principles of Corporate Governance (Paris: OECD Publications Service), p. 11.

${ }^{11}$ Peraturan Menteri Negara Badan Usaha Milik Negara No : Per-01/Mbu/2011 Tentang Penerapan Tata Kelola Perusahaan Yang Baik (Good Corporate Governance) Pada Badan Usaha Milik Negara Pasal 1 No. 1. 
mempertahankan keberadaannya dan hidup berkelanjutan untuk mencapai maksud dan tujuan perusahaan. ${ }^{12}$

Bank Indonesia menerangkan bahwa GCG adalah suatu tata kelola bank yang menerapkan lima prinsip,yaitu a) transparansi adalah keterbukaan dalam mengemukakan informasi yang material dan relevan serta keterbukaan dalam proses pengambilan keputusan,b) akuntabilitas adalah kejelasan fungsi dan pelaksanaan pertanggungjawaban organ bank sehingga pengelolaannya berjalan secara efektif,c) pertanggungjawaban adalah kesesuaian pengelolaan bank dengan peraturan perundangundangan yang berlaku dan prinsip-prinsip pengelolaan bank yang sehat,d) profesional yaitu memiliki kompetensi, mampu bertindak obyektif dan bebas dari pengaruh atau tekanan dari pihak manapun (independen) serta memiliki komitmen yang tinggi untuk mengembangkan bank syariah e) kewajaran yakni keadilan dan kesetaraan dalam memenuhi hak-hak stakeholders berdasarkan perjanjian dan peraturan perundangundangan yang berlaku. ${ }^{13}$

GCG pada dasarnya merupakan suatu sistem yang meliputi input, proses dan outputdan seperangkat peraturan yang mengatur hubungan antarastakeholderterutama dalam arti sempit hubungan antara pemegang saham, dewan komisaris dan dewan direksi demi tercapainya tujuan perusahaan. GCG dimaksudkan untuk mengatur hubungan-hubungan tersebut dan mencegah terjadinya penyimpangan dalam menerapkan strategi perusahaan dan untuk memastikan bahwa apabila terjadi kesalahan-kesalahan maka akan dapat diperbaiki dengan segera. Oleh karenanya, menurut Tricker sebagaimana dikutip oleh Zarkasyi, munculnya GCG akibat terjadinya kesenjangan hubungan yang terjadi dalam perusahaan dengan yang seharusnya terjadi. ${ }^{14}$

Dengan demikian, GCG adalah suatu sistem yang mengatur, mengelola dan mengawasi proses pengendalian usaha untuk menaikkan nilai saham, sekaligus sebagai bentuk perhatian kepada para pemangku kepentingan. GCG diharapkan menjaga keseimbangan antara pencapaian tujuan ekonomi dan tujuan masyarakat. Tantangan yang muncul dalam GCG adalah mencari cara untuk memaksimumkan penciptaan kesejahteraan sedemikian rupa sehingga tidak membebani ongkos yang tidak perlu kepada pihak ketiga atau masyarakat.

\section{B. ImplementasiGCG di Bank Syariah}

Seiring dengan perkembangan industri perbankan syariah yang antara lain ditandai dengan semakin beragamnya produk perbankan syariah dan bertambahnya jaringan pelayanannya, makapenerapan GCG padaindustri perbankan syariah menjadi

${ }^{12}$ Ibid., pasal 4 No. 1 dan 2

${ }^{13}$ PBI No. 11/33/PBI/2009 Tentang Pelaksanaan GCG Bagi BUS Dan UUS Pasal 1 ayat 10.

${ }^{14}$ Moh. Wahyudin Zarkasyi (2008). Good Corporate Governance Pada Perusahaan Badan Usaha Manufaktur, Perbankan Dan Jasa Keungan Lainnya (Bandung: Alfabeta), p. 35. 
semakin penting. Pelaksanaannya pada industri perbankan syariah harus berlandaskan pada lima prinsip dasar: transparansi, akuntabilitas, pertanggungjawaban, profesional,dan kewajaran. ${ }^{15}$

Bank syariah harus memastikan bahwa prinsip-prinsip GCG tersebut telah diterapkan pada setiap aspek bisnis dan di seluruh jajarannya. Penerapan prinsip-prinsip GCG tersebut diperlukan untuk mencapai kesinambungan usaha (sustainability) bank syariah dengan tetap memperhatikan kepentingan para pemegang saham, nasabah serta pemangku kepentingan lainnya. ${ }^{16} \mathrm{Di}$ bawah ini akan dipaparkan mengenai implementasi kelima prinsip dasar GCG tersebut pada bank syariah.

1. Transparansi

Transparansiadalah keterbukaandalam mengemukakan informasi yang material dan relevan serta keterbukaan dalam proses pengambilan keputusan. ${ }^{17}$ Prinsip ini diperlukan agarkegiatan bisnis bank syariah berjalan secara objektif, profesional, dan untuk melindungi kepentingan stakeholder. ${ }^{18}$ Transparansimengandung unsur pengungkapan (disclosure) dan penyediaan informasi secara tepat waktu, memadai, jelas, akurat, dan dapat diperbandingkan serta mudah diakses oleh pemangku kepentingan dan masyarakat. ${ }^{19}$

Dalam menerapkan prinsip transparansi, bank syariah harus menyediakan informasi yang material dan relevan dengan cara yang mudah diakses dan dipahami oleh pemangku kepentingan. Banksyariah juga harus mengambil inisiatif untuk mengungkapkan tidak hanya masalah yang disyaratkan oleh peraturan perundang-undangan, tetapi juga hal yang penting untuk pengambilan keputusan oleh pemegang saham, kreditur, dan pemangku kepentingan lainnya. ${ }^{20}$

2. Akuntabilitas

Akuntabilitas adalah kejelasan fungsi dan pelaksanaan pertanggungjawaban organ bank sehingga pengelolaannya berjalan secara

${ }^{15}$ Penjelasan Atas PBI No. 11/33/PBI/2009 Tentang Pelaksanaan GCG Bagi BUS dan UUS pada bagian Umum.

${ }^{16}$ Komite Nasional Kebijakan Governance (2012). Prinsip Dasar Dan Pedoman Pelaksanaan Good Corporate Governance Perbankan Indonesia (Jakarta: KNKG), p. 6.

${ }^{17}$ Penjelasan Atas PBI No. 11/33/PBI/2009 Tentang Pelaksanaan GCG Bagi BUS dan UUS pada bagian Umum.

${ }^{18}$ Komite Nasional Kebijakan Governance (2012). Prinsip Dasar Dan Pedoman Pelaksanaan Good Corporate Governance Perbankan Indonesia. Jakarta: KNKG, p. 6.

${ }^{19}$ Ibid., p. 6.

${ }^{20}$ Komite Nasional Kebijakan Governance (2006). Pedoman Umum Good Corporate Governance Indonesia, Jakarta: KNKG, p. 5. 
efektif. ${ }^{21}$ Akuntabilitasmengandung unsur kejelasan fungsi dalam organisasi dan cara mempertanggungjawabkannya. Akuntabilitas merupakan prasyarat yang diperlukan untuk mencapai kinerja yang berkesinambungan usaha bank syariah. $^{22}$

Dalam menerapkan prinsip akuntabilitas, bank syariah sebagai lembaga dan pejabat yang memiliki kewenangan harus dapat mempertanggungjawabkan kinerjanya secara transparan dan akuntabel. Untuk itu, bank syariah harus dikelola secara sehat, terukur, dan professional dengan memperhatikan kepentingan pemegang saham, nasabah, dan pemangku kepentingan lain. ${ }^{23}$

3. Responsibilitas

Responsibilitas adalah kesesuaian pengelolaan bank dengan peraturan perundang-undangan yang berlaku dan prinsip-prinsip pengelolaan bank yang sehat. ${ }^{24}$ Prinsip responsibilitas atau pertanggungjawaban diperlukan di bank syariah agar dapat menjamin terpeliharanya kesinambungan usahabank dalam jangka panjang ${ }^{25}$

Dalam menerapkan prinsip responsibilitas, bank syariah harus mematuhi peraturan perundang-undangan yang berlaku dan ketentuan internal bank serta melaksanakan tanggung jawab terhadap masyarakat dan lingkungan sehingga dapat terpelihara kesinambungan usaha dalam jangka panjang dan mendapat pengakuan sebagai warga korporasi yang baik atau dikenal dengan good corporate citizen. ${ }^{26}$ Bank syariah juga harus berpegang pada prinsip kehati-hatian(prudent).

4. Profesional

Profesional yaitu memiliki kompetensi, mampu bertindak obyektif dan bebas dari pengaruh atau tekanan dari pihak manapun (independen) serta memiliki komitmen yang tinggi untuk mengembangkan bank syariah. ${ }^{27}$ Untuk melancarkan pelaksanaan prinsip-prinsip GCG, perusahaan harus

${ }^{21}$ Penjelasan Atas PBI No. 11/33/PBI/2009 Tentang Pelaksanaan GCG Bagi BUS dan UUS pada bagian Umum.

${ }^{22}$ Komite Nasional Kebijakan Governance (2006). Pedoman Umum Good Corporate Governance Indonesia.Jakarta: KNKG, p. 6.

${ }^{23}$ Komite Nasional Kebijakan Governance (2012). Prinsip Dasar Dan Pedoman Pelaksanaan Good Corporate Governance Perbankan Indonesia (Jakarta: KNKG), p. 7. Lihat pula Komite Nasional Kebijakan Governance (2006). Pedoman Umum Good Corporate Governance Indonesia, (Jakarta: KNKG), p. 6.

${ }^{24}$ Penjelasan Atas PBI No. 11/33/PBI/2009 Tentang Pelaksanaan GCG Bagi BUS dan UUS pada bagian Umum.

${ }^{25}$ Komite Nasional Kebijakan Governance (2012). Prinsip Dasar Dan Pedoman Pelaksanaan Good Corporate Governance Perbankan Indonesia (Jakarta: KNKG), p. 8.

${ }^{26}$ Komite Nasional Kebijakan Governance (2006). Pedoman Umum Good Corporate Governance Indonesia, (Jakarta: KNKG), p. 6.

${ }^{27}$ Penjelasan Atas PBI No. 11/33/PBI/2009 Tentang Pelaksanaan GCG Bagi BUS dan UUS pada bagian Umum. 
dikelola secara independen sehingga masing-masing organ perusahaan tidak saling mendominasi dan tidak dapat diintervensi oleh pihak lain. ${ }^{28}$

Profesional mengandung unsur kemandirian dari dominasi pihak lain dan berlaku objektifdalam melaksanakan tugas dan kewajibannya. Dalam hubungan dengan penerapan prinsip profesional, bank syariah harus dikelola secara independen agar masing-masing organ perusahaan beserta seluruh jajaran dibawahnya tidak boleh saling mendominasi dan tidak dapat diintervensi oleh pihak manapun yang dapat mempengaruhi obyektivitas dan profesionalisme dalam melaksanakan tugas dan tanggungjawabnya. ${ }^{29}$

5. Kewajaran

Kewajaranyakni keadilan dan kesetaraan dalam memenuhi hak-hak stakeholders berdasarkan perjanjian dan peraturan perundang-undangan yang berlaku. ${ }^{30}$ Bank syariah harus senantiasa memperhatikan kepentingan pemegang saham dan pemangku kepentingan lainnya berdasarkan asas kewajaran dan kesetaraan. ${ }^{31}$

Kewajaranmengandung unsur perlakuan yang adil dan kesempatan yang sama sesuai dengan proporsinya. Dalam melaksanakan kegiatannya, bank syariah harus senantiasa memperhatikan kepentingan pemegang saham, nasabah dan pemangku kepentingan lainnya berdasarkan prinsip kewajaran dan kesetaraan dari masing-masing pihak yang bersangkutan. ${ }^{32}$

\section{DEWAN PENGAWAS SYARIAH (DPS)}

\section{A. Pengertian Dewan Pengawas Syariah (DPS)}

Bank syariah harus menjalankan fungsinya dengan baik sesuai dengan ketentuan perbankan yang berlaku dan juga sesuai pula dengan prinsip syariah. Untuk menjamin terlaksananya prinsip syariah, dalam aktifitas perbankan syariah terdapat salah satu pihak terafiliasi yaitu Dewan Pengawas Syariah (DPS) yang memberikan jasanya kepada bank syariah. ${ }^{33}$ Dewan inilah sebagai pihak yang bertanggungjawab atas informasi tentang kepatuhan pengelola bank akan prinsip syariah.

\footnotetext{
${ }^{28}$ Komite Nasional Kebijakan Governance (2006). Pedoman Umum Good Corporate Governance Indonesia, (Jakarta: KNKG), p. 7.

${ }^{29}$ Komite Nasional Kebijakan Governance (2012). Prinsip Dasar Dan Pedoman Pelaksanaan Good Corporate Governance Perbankan Indonesia (Jakarta: KNKG), p. 8.

${ }^{30}$ Penjelasan Atas PBI No. 11/33/PBI/2009 Tentang Pelaksanaan GCG Bagi BUS dan UUS pada bagian Umum.

${ }^{31}$ Komite Nasional Kebijakan Governance (2006). Pedoman Umum Good Corporate Governance Indonesia, (Jakarta: KNKG), p. 7.

${ }^{32}$ Komite Nasional Kebijakan Governance (2012). Prinsip Dasar Dan Pedoman Pelaksanaan Good Corporate Governance Perbankan Indonesia (Jakarta: KNKG), p. 6.

${ }^{33}$ Undang-Undang No.21/2008 Tentang Perbankan Syariah Pasal 1 No. 15 poin a.
} 
Menurut Muhammad, Dewan Pengawas Syariah (DPS) adalah dewan yang melakukan pengawasan terhadap prinsip syariah dalam kegiatan usaha bank syariah yang dalam menjalakan fungsinya bertindak secara independen. ${ }^{34}$ DPS terdiri dari orang-oang yang memiliki kemampuan, baik di bidang hukum muamalah, hukum ekonomi dan perbankan, serta kemampuan lain yang relevan dengan tugas kesehariannya. ${ }^{35}$ Anggota DPS juga harus memiliki integritas, kompetensi dan reputasi keuangan. ${ }^{36}$

Menurut Arifin, DPS adalah badan independen yang ditempatkan oleh Dewan Syariah Nasional (DSN) yang berada pada suatu bank syariah. ${ }^{37}$ Anggota DPS terdiri dari pakar di bidang syariah muamalah yang juga mengetahui pengetahuan umum di bidang perbankan. Dalam melaksanakan tugasnya, DPS wajib mengikuti fatwa DSN mengenai kesesuain produk dan jasa bank dengan ketentuan dan prinsip syariah. Tugas utamanya adalah mengawasi kegiatan usaha lembaga keuangan syariah agar sesuai dengan ketentuan dan prinsip syariah yang telah difatwakan oleh DSN. ${ }^{38}$

Sedangkan, Dewan Syariah Nasional (DSN) Majelis Ulama Indonesia (MUI) menerangkan bahwa DPS adalah badan yang ada di Lembaga Keuangan Syariah (LKS) yang bertugas mengawasi pelaksanaan keputusan DSN di lembaga keuangan syariah. ${ }^{39}$ Anggota DPS diusulkan oleh Rapat Umum Pemegang Saham (RUPS) dan penempatannya di bank syariah harus mendapatkan persetujuan DSN. Fungsi utamanya adalah sebagai penasehat dan pemberi saran kepada direksi, pimpinan unit usaha syariah, dan pimpinan kantor cabang syariah mengenai hal-hal yang terkait dengan aspek syariah.

Accounting and Auditing Organization for Islamic Financial Institutions (AAOIFI) ${ }^{40}$ dalam Governance Standard for Islamic Financial Institutions (GSIFI) nomor 1 paragraf 2 menyatakan bahwa:

${ }^{34}$ Muhammad (2001). Audit Dan Pengawasan Syariah Pada Bank Syariah Catatan Pengalaman, (Yogyakarta: UII Press), p. 18.

${ }^{35}$ Ibid.p. 18.

${ }^{36}$ PBI No.6/17/PBI/2004 Tentang Bank Perkreditan Rakyat Berdasarkan Prinsip Syariah Pasal 28.

${ }^{37}$ Zainul Arifin (2005). Dasar-Dasar Manajemen Bank Syariah, (Jakarta: Pustaka Alvabet), p. 106.

${ }^{38}$ Ibid., p. 106.

${ }^{39}$ Majelis Ulama Indonesia, Keputusan DSN MUI No: 01/2000 Tentang Pedoman Dasar DSN MUI.

${ }^{40} \mathrm{AAOIFImerupakan}$ sebuah lembaga non profit internasional independen yangmenyiapkan akutansi, auditing, tata kelola perusahaan, kode etik, dan standar syariah bagi perbankan syariah dan lembaga-lembaga keuangan syariah lainnya. AAOIFI didirikan di Al Jazair sesuai dengan persetujuan beberapa lembaga keuangan syariah bersekala internasional pada tanggal 1 Shafar 1410/26 Februari 1990. Organisasi ini beroperasi secara resmi pada tanggal27 Maret 1991 dan berkedudukan di Manama Bahrain. 
"A shari'a supervisory board is an independent body of specialised jurists in fiqih mua'amalat (Islamic commercial jurisprudence). However, the shari'a supervisory board may include a member other than those specialised in fiqih mua'amalat, but who should be an expert in the field of Islamic Financial Institutions and with knowledge of fiqih mua'amalat.". ${ }^{41}$

Artinya: "Dewan Pengawas Syariah adalah lembaga independen yang mempunyai sepesialisasi keahlian dalam fikih muamalah (hukum keuangan Islam). Namun demikian, anggota Dewan Pengawas Syariah tidak hanya (dituntut) mempunyai spesialisi dalam fikih muamalah, tetapi juga harus ahli dalam dalam bidang lembaga keuangan Islam dan mempunyai pengetahuan tentang fikih muamalah.”

DPS wajib mengacu pada fatwa-fatwa DSN dalam melaksanakan tugasnya. Sejak awal bank syariah harus menyertakan calon anggota DPSnya untuk dimintakan rekomendasi dari DSN dan selanjutnya dilakukan uji kelayakan dan kepatutan oleh Bank Indonesia. Sebagai pengawas syariah, fungsi DPS sangat strategis dan mulia, karena menyangkut kepentingan seluruh pengguna lembaga tersebut. Umat Islam akan selalu berpedoman pada keberadaan DPS karena dari sinilah kepercayaan pada bank syariah tersebut ditumbuhkan.

Jumlah anggota DPS di bank syariahsedikitnya dua orang dan sebanyakbanyaknya setengah dari jumlah Direksi. Masa jabatannya paling lama sama dengan jabatan anggota Direksi atau Dewan komisaris. ${ }^{42}$ Anggotanya hanya boleh merangkap jabatan sebagai anggota DPS sebanyak-banyaknya pada dua lembaga perbankan dan dua lembaga keuangan syariah non bank. Satu anggota DPS diperbolehkan merangkap jabatan sebagai anggota DSN. Anggota DPS digolongkan sebagai pihak terafiliasi bank syariah. ${ }^{43}$

\section{B. Peran DPS dalam imlementasi GCG di bank syariah}

Peran merupakan suatu pola sikap, nilai dan tujuan yang diharapkan dari seseorang yang berdasarkan posisinya di masyarakat. Posisi ini merupakan identifikasi dari status atau tempat seseorang dalam suatu sistem sosial dan merupakan perwujudan aktualisasi diri. Menurut Kamus Besar Bahasa Indonesia, peran adalah perangkat tingkah laku yang diharapkan dimiliki oleh seseorang yang berkedudukan dalam masyarakat. ${ }^{44}$ Sedangkan, menurut C. P. Chaplin, peran adalah fungsi individu atau peranannya dalam satu kelompok atau institusi. Menurutnya, peran juga merupakan

${ }^{41}$ AAOIFI (1999). Accounting and Auditing and Governance Standard for Islamic Financial Institutions,(Manama, Bahrain: AAOIFI), p. 1.

${ }^{42}$ Surat Edaran Bank Indonesia No. 12/13/DPbs Tentang Pelaksanaan GCG bagi BUS dan UUS bagian masa jabatan anggota DPS.

${ }^{43}$ Peraturan Bank Indonseia No. 6/17/PBI/2004 Tentang Bank Perkreditan Rakyat Berdasarkan Prinsip Syariah Pasal 30 ayat 1- 4 .

${ }^{44}$ Tim Penyusun Kamus Pusat Bahasa (2007). Kamus Besar Bahasa Indonesia ed. III, cet. IV, (Jakarta: Balai Pustaka), p. 854. 
fungsi atau tingkah laku yang diharapkan ada pada individu atau yang menjadi ciri atau sifat dari dirinya. ${ }^{45}$

Dalam psikologi sosial menurut Arthur dan Emily, peran pada umumnya mengacu kepada pola perilaku apapun yang melibatkan hak, kewajiban dan tugas tertentu yang diharapkan dari seseorang, dapat dilatih dan diperkuat untuk ditampilkan di dalam situasi sosial tertentu. ${ }^{46}$ Dalam melakukan perannya seseorang dipengaruhi oleh keadaan sosial baik dari dalam maupun dari luar dan bersifat stabil. Dengan demikian, peran adalah seperangkat tingkah laku yang diharapkan oleh orang lain terhadap seseorang sesuai kedudukannya dalam suatu sistem.

AAOIFI dalam Governance Standard for Islamic Finacial Institutions (GSIFI) menjelaskan bahwa peran DPS adalahdirecting, reviewing and supervising the activities of Islamic Financial Institution in orderto ensure that they are in compliance with Islamic shari'a rules and principles. ${ }^{47}$ Artinya, peran DPS yakni mengarahkan, menilai,dan mengawasi seluruh aktivitas institusi keuangan Islam untuk memastikan aktivitasnya sesuai prinsip dan aturan syariah.Dengan demikian, menurut AAOIFI ada tiga peran DPS di lembaga keuangan syariah, yaitu melakukan penilaian, pengarahan dan pengawasan atas aktivitas bank syariah agar sesuai dengan aturan dan prinsip syariah.

Selain tiga peran di atas, DSN MUI menambahkan satu peran DPS yaitu melakukan sosialisasi dan edukasi kepada masyarakat tentang bank syariah melalui media-media yang sudah berjalan di masyarakat, seperti khutbah, majelis ta'lim, pengajian-pengajian. ${ }^{48}$ Atau, lebih tepatnya peran DPS menurut DSN MUI tersebut adalah sebagai pihak yang juga ikut memasarkan (marketing) bank syariah kepada masyarakat.

Memperhatikan kepada peran DPS menurut AAOIFI dan DSN-MUI, makaperan DPS dalam implentasi prinsip-prinsip GCG di bank syariah adalah sebagai berikut:

1. Directing yaitu memberikan pengarahan, pemikiran, saran dan nasehat kepada direksi bank syariah mengenai hal-hal yang berkaitan dengan aspek syariah.

2. Reviewing yaitu mencermati, memeriksa, mengkaji dan menilai implementasi fatwa DSN pada operasional bank syariah.

3. Supervisingyaitu melaksanakan tugas pengawasan baik secara aktif maupun secara pasif atas implementasi fatwa DSN pada operasional bank syariah.

${ }^{45}$ C. P. Chaplin (1981). Dictionary of Phsychology. Kartini Kartono et al. (terj), Kamus Lengkap Psikologi (Jakarta: PT RajaGrafindo Persada), p. 439.

${ }^{46}$ Arthur S. Reber dan Emily S Reber (2010). The Penguin Dictionary of Phsychology. Yudi Santoso et al (terj.), Kamus Psikologi, cet. I (Yogyakarta: Pustaka Pelajar), p. 838.

${ }^{47}$ AAOIFI (1999). Accounting and Auditing and Governance Standard for Islamic Financial Institutions,(Manama, Bahrain: AAOIFI), p. 1.

${ }^{48}$ Majelis Ulama Indonesian, Keputusan DSN MUI, No.Kep-98/MUI/III/2001 Tentang Susunan Pengurus DSN-MUI Bagian Peran DPS. 
4. Marketing yaitu melakukan sosialisasi dan edukasi kepada masyarakat tentang bank syariah melalui media-media yang sudah berjalan di masyarakat, seperti khutbah, majelis ta'lim, pengajian-pengajian. ${ }^{49}$

DPS dalam struktur bank syariah berada setingkat dengan komisaris sebagai pengawas direksi. ${ }^{50}$ Jika komisaris adalah sebagai pengawas kinerja manajemen bank, maka DPS adalah pengawas menejemen bank yang berkaitan dengan operasionalnya sehari-hari agar selalu sesuai dengan prinsip syariah yang difatwakan oleh Dewan Syariah Nasional (DSN). ${ }^{51}$ Keberadaan DPS di bank syariah sangat penting sebagai pihak yang berperan di dalam mengawasi operasionalnya agar benar-benar berjalan di atas rel syariah. DPS diharapkan dapat menjamin dan memastikan bahwa suatu bank syariah dalam semua kegiatannya telah menerapkan prinsip syariah.

\section{KESIMPULAN}

Implementasi GCG di banksyariah berlandaskanlima prinsip, yaitu transparansi, akuntabilitas, pertanggungjawaban, profesional dan kewajaran. Dalam rangka menerapkan kelima prinsiptersebut, bank syariah harus memenuhi prinsip syariah. Karenanya, peranDPSdalam implementasi GCG menjadi sangat penting yaitu mengawasi dan memastikan bahwa suatu bank syariah dalam operasionalnya telah sesuai dengan prinsip syariah.

Peran DPS dalam implementasi prinsip-prinsip GCG di bank syariah adalah 1)memberikan pengarahan, pemikiran, saran dan nasehat kepada direksi bank syariah mengenai hal-hal yang berkaitan dengan aspek syariah, 2) mencermati, memeriksa, mengkaji dan menilai implementasi fatwa DSN pada operasional bank syariah, 3) melaksanakan tugas pengawasan baik secara aktif maupun secara pasif atas implementasi fatwa DSN pada operasional bank syariah, 4) yaitu melakukan sosialisasi dan edukasi kepada masyarakat tentang bank syariah melalui media-media yang sudah berjalan di masyarakat, seperti khutbah, majelis ta'lim, pengajian-pengajian.

\section{DAFTAR PUSTAKA}

Accounting and Auditing Organization for Islamic Financial Institution (1999), Accounting and Auditing and Governance Standard for Islamic Financial Institutions. Manama Bahrain: AAOIFI.

Archer, Simon dan Karim, Rifaat Ahmed Abdel, Islamic Finance, Singapore: John Welley and Sons, 2007.

\footnotetext{
${ }^{49}$ Ibid.

${ }^{50}$ Majelis Ulama Indonesian, KeputusanDSN-MUI No. 98/MUI/III/2001 Bagian Struktur DPS.

${ }^{51}$ Majelis Ulama Indonesian, Keputusan DSN-MUI No. 98/MUI/III/2001 Bagian Peranan DPS.
} 
Arifin, Zainul (2005), Dasar-Dasar Manajemen Bank Syariah. Jakarta: Pustaka Alvabet.

Bank Indonesia (2011), Statistik Perbankan Syariah. Jakarta: Bank Indonesia.

Chaplin, C. P. (1981), Dictionary of Phsychology. Kartini Kartonoet al (terj.), Kamus Lenkap Psikologyi. Jakarta: PT RajaGrafindo Persada.

Chapra, M. Umer dan Ahmed, Habib (2002), Islamic Governance In Islamic Financial Institutions. Jeddah: Islamic Research and Islamic Institute, Islamic Development Bank.

Chapra, M. Umer and Khan, Tariqullah (2000), Regulation And Supervision Of Islamic Banks. Jeddah: Islamic Research and Training Institute, Islamic Development Bank.

Grais, Wafik and Pellegrini, Matteo (2006), Corporate Governance and Shariah Compliance in Institutions Offering Islamic Financial Services. Policy Research Working Paper World Bank, dikutip dari www.econ.worldbank.org/accessed 5 Juli 2009.

K. Lewis, Mervyn dan M. Algaud, Latifa (2007), Islamic Banking. Burhan Subrata et al. (terj.), Perbank Syariah. Jakarta: PT Serambi Ilmu Semesta.

Keputusan Dewan Syariah Nasional (DSN) Majelis Ulama Indonesia (MUI) No. 02/2000 Tentang Pedoman Rumah Tangga Dewan Syariah Nasional.

Komite Nasional Kebijakan Governance (2006), Pedoman Umum Good Corporate Governance Indonesia. Jakarta: KNKG.

Komite Nasional Kebijakan Governance (2012), Prinsip Dasar Dan Pedoman Pelaksanaan Good Corporate Governance Perbankan Indonesia. Jakarta: KNKG.

Muhammad (2001), Audit Dan Pengawasan Syariah Pada Bank Syariah Catatan Pengalaman. Yogyakarta: UII.

Majelis Ulama Indonesia, Keputusan DSN MUI No: 02/2000 Tentang Pedoman Rumah Tangga DSN MUI.

Majelis Ulama Indonesia, Keputusan DSN MUI No: 03/2000 Tentang Petunjuk Pelaksanaan Penetapan Anggota DPS Pada LKS.

Majelis Ulama Indonesia, Keputusan DSN MUI No: 01/2000 Tentang Pedoman Dasar DSN MUI.

OECD (2004), OECD Principles of Corporate Governance. Paris: OECD Publications Service.

Peraturan Bank Indonesia Nomor 8/14/PBI/2006 Tentang Perubahan Atas Peraturan Bank Indonesia Nomor 8/4/PBI/2006 Tentang Pelaksanaan Good Corporate Governance Bagi Bank Umum.

Peraturan Bank Indonesia No. 11/15/PBI/2009 Tentang Perubahan Kegiatan Usaha Bank Konvensional Menjadi Bank Syariah. 
Akhmad Faozan: Implementasi Good Corporate Governance...

Peraturan Bank Indonesia No. 11/33/PBI/2009 Tentang Pelaksanaan Good Corporate Governance Bagi Bank Umum Syariah Dan Unit Usaha Syariah.

Peraturan Bank Indonesia No. 6/17/PBI/2004 Tentang Bank Perkreditan Rakyat Berdasarkan Prinsip Syariah.

Peraturan Bank Indonesia Nomor 8/4/PBI/2006 Tentang Pelaksanaan Good Corporate Governance Bagi Bank Umum.

Surat Edaran Bank Indonesia (SEBI) Kepada Semua Bank Yang Melaksanakan Kegiatan Usaha Berdasarkan Prinsip Syariah Di Indonesia No.8/19/Dpbs Tanggal 24 Agustus 2006.

Surat Edaran Bank Indonesia (SEBI) No. 11/ 25 /Dpbs/2009 Kepada Kepada Semua Bank Perkreditan Rakyat Di Indonesia.

Syakhroza, Akhmad (2008), Corporate Governance, Sejarah dan Perkembangan, Teori, Model dan Sistem Governance Serta Aplikaasinya dan Pada Perusahaan BUMN. Jakarta: Lembaga Penerbitan FEUI.

Tim Penyusun Kamus Pusat Bahasa (2007), Kamus Besar Bahasa Indonesia. Jakarta: Balai Pustaka.

Undang-Undang No. 10/1998 Tentang Perubahan Atas Undang-Undang No. 7/1992 Tentang Perbankan.

Undang-Undang No. 21 Tahun 2008 Tentang Perbankan Syariah.

Zarkasyi, Moh. Wahyudin (2008), Good Corporate Governance Pada Perusahaan Badan Usaha Manufaktur, Perbankan Dan Jasa Keungan Lainnya. Bandung: Alfabeta. 